\title{
Memórias de normalistas: inserção profissional de professoras
}

Memories of normalists: professional sertion of teachers

Memorias de normalistas: inserción profesional de profesoras

Raquel Silveira Martins de Melo ${ }^{1}$

\section{Resumo}

Esse artigo busca apresentar resultados de pesquisa sobre a escolha do magistério como forma de inserção profissional para normalistas que frequentaram a Escola Normal Nossa Senhora de Oliveira, em Oliveira, Centro-oeste de Minas Gerais, entre os anos 1971 e 1974. Nesse sentido, as ideias que permeiam esse esboço vão ao encontro das concepções e conceitos sobre a mulherprofessora, a formação de professores, em especial para o antigo ensino primário, e a história da educação em Minas Gerais. A metodologia utilizada é concernente à pesquisa narrativa e os dados terão como fonte principal narrativas orais de formandas da referida escola normal no período assinalado.

Palavras-chave: normalistas; feminilização, escola normal, pesquisa narrativa.

\footnotetext{
${ }^{1}$ Mestre em Educação pela Universidade Federal de Ouro Preto. Professora da Escola Estadual Henrique Galvão (Divinópolis/MG). E-mail: raquelsmartins@gmail.com
} 


\begin{abstract}
This article aims to present research results on the choice of teaching as a form of professional insertion for normalistas who attended the Normal School of Our Lady of Oliveira, Oliveira, Midwest of Minas Gerais, between 1971 and 1974. In this sense, the ideas that pervade this outline will meet the ideas and concepts of the woman - teacher, teacher training, especially for the old primary school, and the history of education in Minas Gerais. The methodology used is concerning the narrative research and data will have as the main source of oral narratives trainees said normal school in the indicated period.
\end{abstract}

Keywords: normalistas ; feminization, normal school, narrative research.

\title{
Resumen
}

Este artículo busca presentar resultados de investigación sobre la elección del magisterio como forma de inserción profesional para normalistas que asistieron a la Escuela Normal Nuestra Señora de Oliveira, en Oliveira, Centro-oeste de Minas Gerais, entre los años 1971 y 1974. En ese sentido, las ideas que permean este esbozo van al encuentro de las concepciones y conceptos sobre la mujer-profesora, la formación de profesores, en especial para la antigua enseñanza primaria, y la historia de la educación en Minas Gerais. La metodología utilizada es concerniente a la investigación narrativa y los datos tendrán como fuente principal narrativas orales de formandas de la referida escuela normal en el período señalado.

Palabras clave: normalistas; la feminización, la escuela normal, la investigación narrativa. 


\section{Introdução}

Ouvir, reconhecer e compreender o outro. Narrar e lembrar. Os resultados de pesquisa discutidos nas páginas seguintes consideram a importância das lembranças no processo de (re)significação de momentos importantes na vida do sujeito, bem como das relações estabelecidas com os pares, os lugares transitados, as experiências vividas e os diversos questionamentos que o sujeito se impõe - ou lhe são impostos - durante a vida.

Nessa perspectiva, essa pesquisa versa especialmente sobre a escolha do magistério como forma de inserção profissional para normalistas que frequentaram a Escola Normal Nossa Senhora de Oliveira, em Oliveira, Centro-oeste de Minas Gerais, entre os anos 1971 e 1974. Assim, as ideias que permeiam essas páginas vão ao encontro das concepções e conceitos sobre a mulher-professora, a formação de professores, em especial para o antigo ensino primário, e a história da educação em Minas Gerais. Cumpre iniciar essa discussão com a compreensão da escola normal como lócus privilegiado de formação de professoras primárias.

Segundo Tanuri (2000), o estabelecimento de escolas destinadas à preparação dos docentes das chamadas "primeiras letras" está ligado à institucionalização da instrução pública num contexto em que as noções de secularização e de expansão da educação a todas as camadas sociais estavam em grande voga. É possível situar tal época à Revolução Francesa, quando além do ensino estar a cargo do Estado, multiplicaram-se as escolas normais.

No Brasil, as primeiras situam-se no âmbito das províncias após as mudanças propostas pela reforma constitucional de 12/8/1834. No entanto, como a autora assinala "em todas as províncias as escolas normais tiveram uma trajetória incerta e atribulada, submetidas a um processo contínuo de criação e extinção, para só lograram algum êxito após 1870." (TANURI, 2000, p.64)

O mesmo se deu com a Escola Normal Nossa Senhora de Oliveira. Amaral (2011) data a criação do colégio em 1886 com o nome de Colégio Nossa Senhora da Piedade. Este se mudou, dando origem a outro colégio, que finalmente adota o nome ${ }^{2}$ de "Colégio Nossa Senhora de Oliveira" instituído pelo decreto 1845 de 15/06/1905. Em 1934, o colégio passa da iniciativa particular para as mãos de religiosas da Ordem das Escolápias. Nesse ponto, cabem algumas considerações:

A Igreja Católica mostrando-se aliada aos interesses das oligarquias permaneceu dirigindo boa parte do ensino destinado às mulheres, por meio dos seus colégios religiosos, que foram responsáveis pela educação das filhas da elite, apoiando a formação diferenciada dos sexos. Nesse contexto, ela prevalecia com o maior número de escolas femininas. Os seus colégios, por não serem gratuitos, não possibilitavam o acesso às camadas desfavorecidas da sociedade. (ROSSI; INÁCIO FILHO, 2006, p.88)

Segundo os autores, é possível compreender que havia uma escassez de escolas públicas em Minas Gerais, fazendo com que parte das famílias que tinham condições financeiras buscasse os estabelecimentos particulares católicos para educação das filhas. Esses locais foram responsáveis por parte importante da formação das professoras primárias do período.

\footnotetext{
${ }^{2}$ A autora também chama a atenção que em 1974, a escola, por decreto do governo federal, passa a se chamar "Escola Nossa Senhora de Oliveira $-1^{\circ}$ e $2^{\circ}$ graus". (AMARAL, 2011, p.569)
} 
Tanuri (2000) corrobora com a questão ao contabilizar que em Minas Gerais no período de fundação da escola havia 12 escolas de iniciativa privada, duas municipais e apenas uma estadual. Pode-se inferir, portanto, que a formação das professoras primárias estava praticamente a cargo dessas iniciativas. E mais, é possível compreender que esse quadro não é modificado, ao menos até meados da década de 1950, quando a maior parte das escolas normais ainda estava, no estado, sob a égide da iniciativa particular. (TANURI, 2000, p.77)

Importa ressaltar ainda ponto importante no que tange ao Colégio Nossa Senhora de Oliveira e muitas outras escolas normais, em especial as confessionais: era um colégio feminino. E essa característica, marca toda uma definição sobre a inserção e a profissionalização no magistério. Souza (2007) ao tratar de memórias de normalistas na década de 1950 assinala que

com relação à formação acadêmica e profissional da mulher [...], o ingresso no Instituto de Educação alcançava o estatuto de um rito de passagem. Rito esse dos mais significativos na vida das jovens, pois o sucesso obtido pela distinção em ser uma normalista daquela instituição já representava para muitas moças, principalmente daquelas oriundas das classes médias baixas, a certeza do ingresso direto no magistério público, viabilizando uma carreira bem vista pela sociedade e um futuro promissor.(SOUZA, 2007, p.30.)

O momento da entrada na escola normal apresenta-se como algo marcante na vida daquelas moças, não apenas como uma nova etapa na constituição da sua formação intelectual ou ainda no reconhecimento da maturidade, mas principalmente, num momento em que há uma definição, mesmo que não de ordem pessoal do destino profissional como professora primária.

A questão da possibilidade de inserção profissional através da entrada nas escolas formadoras de professoras primárias ganha uma complexidade a mais ao se considerar o período imediatamente posterior à reforma educacional proposta pelo governo militar (1964-1985).

A Lei 5.692/71 que estabeleceu diretrizes e bases para o primeiro e segundo graus contemplou a escola normal e, no bojo da profissionalização obrigatória adotada para o segundo grau, transformoua numa das habilitações desse nível de ensino, abolindo de vez a profissionalização antes ministrada em escola de nível ginasial. Assim, a já tradicional escola normal perdia o status de "escola" e, mesmo, de "curso", diluindo-se numa das habilitações profissionais do ensino de segundo grau. (TANURI, 2000, p.80.)

Num contexto de dissolução da antiga forma do curso normal, descortinavam-se para aquelas moças novas possibilidades de inserção profissional - através das diferentes habilitações no ensino secundário -, no entanto, qual o significado para elas da entrada e "escolha" pela habilitação no magistério? O descortinar dessa questão permite compreender não apenas as vivências daquelas moças, mas também as possibilidades profissionais para as mulheres no período. Suas escolhas descortinam a posição -a ser -ocupada - ou almejada dessas mulheres da época. 
Para alcançar tal questão seria imperioso ouvir as histórias rememoradas das mulheres que viveram o período de 1971-1974³ como normalistas na “antiga Escola das Madres" é nesse sentido que se opta pela pesquisa narrativa como opção metodológica, e pelos relatos narrados como fonte principal para o desenvolvimento desta pesquisa.

Em se tratando das diversas justificativas para o uso das narrativas é importante relembrar que essa metodologia surge como uma alternativa à sociologia positivista, sendo aplicada pela primeira vez por sociólogos americanos nas décadas de 1920 e 1930. Atualmente, percebe-se que o uso da metodologia narrativa tem atingido grandes proporções, Ferraroti (2010) argumenta que isso se deve por dois motivos principais: o primeiro é uma necessidade de renovação nos métodos da sociologia clássica; o outro seria a necessidade de renovação no campo da antropologia ligado às tendências de investigação do cotidiano e suas relações.

As explicações estruturais e de categorias gerais já não mais satisfazem os interlocutores; as pessoas querem compreender seu cotidiano, seus problemas, suas tensões. Assim, se percebe uma valorização não apenas do saber prático, mas dos conhecimentos e saberes produzidos na prática e aqueles desenvolvidos pelos educadores em outros momentos e espaços de vivências e experiências. É na esteira dessas reflexões, que a pesquisa (auto)biográfica e a pesquisa relatada nessas páginas, em especial estudos que se debruçam sobre histórias de vida de professores, é impulsionada tendo em vista, principalmente, a importância de valorizar as vozes, os sujeitos e seus saberes.

\section{A opção pela pesquisa narrativa}

Narrar é antes de tudo compartilhar das experiências vividas e experimentadas por um e pelo outro, é uma constante relação entre o que se diz de si mesmo e a parte de si que é do coletivo. A pesquisa narrativa pretende captar nas histórias dos sujeitos o conhecimento sobre a formação, as sensações, as experiências. O uso de narrativas como fonte está intrinsecamente ligado a uma dimensão principal: o ser humano conta histórias o tempo todo, comunica a sua vida e, ao fazê-lo, narra suas experiências, em suma, a narrativa faz parte do cotidiano. Segundo Freitas e Fiorentini:

Na qualidade de seres humanos interpretamos e narramos nossas vidas e experiências segundo nossos valores e crenças, os quais, por sua vez, variam de acordo com o tempo e o lugar que ocupamos na sociedade. As histórias que contamos são o meio pelo qual tentamos capturar e traduzir a complexidade e as múltiplas relações que atravessam nossas experiências. (FREITAS; FIORENTINI, 2007, p.64.)

A fala dos referidos autores é emblemática para o entendimento de outra dimensão do uso da narrativa. Eles apontam que há uma multiplicidade de experiências e relações que envolvem cada indivíduo essas são cristalizadas pelas narrativas que este conta. No entanto, destacam que narrar é uma forma de (re)significar as experiências vividas por cada indivíduo que ocupa determinado lugar no tempo e no espaço. Considerando então que cada ser humano ocupa posição singular e múltipla - por se envolver em vários grupos sociais - através das narrativas, o homem (re)significa e traduz essas experiências.

\footnotetext{
3 Assinala-se esse período, pois foi o imediatamente posterior à reforma de 1971, assim essas alunas já frequentaram currículos novos, além de concepções diferentes sobre sua formação.
} 
Na mesma linha de reflexão, Mello (2004) acrescenta a noção de que o entendimento de uma história requer a percepção do outro e de que o lugar ocupado no presente interfere na compreensão do passado, bem como no seu desdobramento para o futuro. Entende-se, como Cunha (2009), que o narrador se situa em uma tríade temporal: presente, passado e futuro. Esses tempos estão diretamente relacionados à própria percepção do "eu" pelo sujeito-narrador.

Ao relatar, o sujeito rememora o que ele, no presente, julga ser a si mesmo no passado e, ao mesmo tempo, projeta o futuro. "Em outras palavras, a história é narrada no presente, mas remete tanto o autor quanto o ouvinte às experiências vivenciadas no passado, com projeções para o futuro." (CUNHA, 2009, p.8)

As narrativas guardam as ambiguidades e esquecimentos que são aspectos de sua especificidade, ou seja, o tempo narrado não é linear e envolve dimensões não apenas do vivido, mas também do rememorado, dessa forma as narrativas não expressam a realidade como foi, mas sim como é lembrada e, ressalta-se, rememorada a partir de uma posição do presente. Esse movimento tal qual uma corrente faz uma relação tênue e constante entre o presente e o passado, as lembranças são marcadas pela multiplicidade de grupos e relações sociais que o indivíduo está envolvido simultaneamente tal qual se julgam aqui ser as narrativas.

Chamon (2005) assinala ainda o porquê das mulheres estarem constantemente excluídas dos documentos oficiais, se faz necessário o uso de documentos íntimos para pesquisar sua presença e influência em aspectos da vida pública. Atualmente, entre as fontes para a discussão sobre o feminino estão os relatos orais. "Tais fontes possibilitam uma maior compreensão das dimensões privadas formais e informais da educação - nas relações parentais, nas associações, nas escolas e na sociedade em geral." (CHAMON, 2005, p.17.)

Esse é o ponto essencial nesta pesquisa, uma vez que se entende que para cada um dos sujeitos que compõem os dados dessa pesquisa há uma distância temporal e mais, uma posição social bem diferente daquela que era ocupada no momento em que ingressaram na "antiga escola das Madres". As lembranças que são os dados principais dessa pesquisa, além de permeadas da emoção do narrar, trazem também essencialmente traços do presente.

Nosso principal objetivo é compreender em que medida a opção por se formar no antigo Normal era uma estratégia de inserção profissional. Para tanto a pesquisa foi elaborada sobre o eixo de três etapas, sendo a principal delas as entrevistas narrativas com antigas normalistas.

Na primeira etapa, foi realizada uma pesquisa documental sobre a Escola Normal Nossa Senhora de Oliveira, direcionando a análise para as documentações relativas às turmas de formandas entre os anos de 1971 e 1975. Essa documentação - guardada no arquivo de Escolas Extintas da Superintendência De Ensino de Divinópolis - limita-se a alguns livros de entrega de diplomas, atas de aprovação em provas "finais" e o que foi a essa pesquisa mais caro, registros das notas e das matrículas de alunas.

Os documentos permitiram construir uma relação entre as alunas que entraram na escola para fazer todo o curso ginasial e normal e aquelas que apenas ingressaram no Normal. Foi possível ainda eliminar as alunas que não finalizaram o curso e perceber os nomes que se repetiram ano a ano. Formando assim um grupo de moças que conviveram juntas por mais de 6 anos.

Na segunda etapa, foi elaborado um quadro em que foram postas as informações básicas contidas nos documentos sobre as referências das moças - quem eram seus pais, onde eles moravam, qual a profissão destes -, tal etapa se deve essencialmente para o achado dessas moças quase 30 anos depois da formatura. Após essa etapa, uma dessas moças foi encontrada e propiciou o encontro com outras que também foram convidadas a participar da pesquisa através de entrevistas narrativas. 
Os sujeitos que compõem a pesquisa são, pois, algumas daquelas moças formandas de $1974^{4}$ - ou seja, que vivenciaram as primeiras mudanças decorrentes da Reforma de 1971 -, uma vez que, com a reforma, o ensino chamado de científico abarcava novas possibilidades de qualificação e inserção. Outro critério na escolha dos sujeitos é que tenham exercido - ou estejam exercendo -o magistério, chegando a se aposentar. Tal critério recai na compreensão de que a posição dentro do grupo dos professores - seja de aposentados ou não - ressignifica o momento de escolha pelo magistério. Permitindo ao sujeito determinar, na posição do hoje, a importância daquele momento e as decisões tomadas no passado, bem como suas consequências.

Os sonhos, vontades e vivências nos primeiros tempos como normalistas, em especial aqueles que delineavam/imaginavam a carreira no magistério, foram buscados junto a entrevistas narrativas. Momentos em que os sujeitos discorreram livremente sobre sua(s) história(s), a partir de uma questão direta simples: "Diga como foi a escolha de entrar na escola das madres: o que se buscava? Foi alcançado?"

A posição do(s) entrevistador(es) nesses momentos foi a de ouvinte atento, sempre a postos para proporcionar ensejos a mais lembranças. Cumpre salientar ainda que essas entrevistas foram numa terceira etapa transcritas e passadas por revisão pelo próprio sujeito, de forma que ele pode definir se a transcrição condiz fielmente com o momento da narrativa.

\section{As narrativas e os sujeitos: um primeiro olhar}

Os momentos das três entrevistas que já foram transcritas e analisadas ${ }^{5}$ foram de grande emoção. Apesar de um instante inicial de surpresa e espanto, as entrevistadas se dispuseram a lembrar dos dias como normalistas, da entrada na "Escola das Madres" - como a Escola Normal Nossa Senhora de Oliveira é por elas tratada - e recordaram fatos importantes, emocionantes e saudosos da escola, das colegas, dos professores.

Duas questões são bastante pertinentes sobre essas memórias como um todo, o primeiro deles é o contato inicial com as normalistas. Diante de um espanto e receio, a principal admiração dessas mulheres era se sentir importante como sujeito que participou de algo maior do que elas, no seu próprio entender.

Essa mesma surpresa foi verificada por Mignot (2007) quando pesquisava papéis guardados de professoras. As formas de lembrança das docentes vão desde o narrar a própria história em foro íntimo até a participação numa pesquisa como essa. "O tom de surpresa e descoberta da importância atribuída aos registros docentes [...] deixa entrever, diferentemente do que o suposto, que as professoras escrevem e inscrevem seus sonhos, projetos e práticas muito mais do que o imaginado." (MIGNOT, 2007, p.42)

Importa supor ainda que essa surpresa esteja ligada à pequena importância do sujeito sobre as suas lembranças, considerado como passado, vivido e acabado. Bem como um desmerecimento daquilo que foi experienciado. Ao tratar da pesquisa narrativa, Passeggi et al (2011) corroboram com essa discussão ao apontar que faz parte do âmbito dessa pesquisa compreender como:

\footnotetext{
${ }^{4}$ Nesse sentido, sem a análise prévia da documentação é impossível delimitar o número dessas mulheres.

${ }^{5}$ Importa ressaltar que a pesquisa que deu origem a este artigo entrará numa segunda fase, quando serão feitas entrevistas com as professoras leigas que instruíram essas moças e hoje ainda são professoras em cursos de Licenciatura.
} 
Os indivíduos dão forma à suas experiências e sentido ao que antes não tinha como constroem a consciência histórica de si e de suas aprendizagens nos territórios que habitam e são por eles habitados, mediante os processos de biografização. (PASSEGGI et. al, 2011, p.371.)

O processo de narrar a entrada na escola e os anos lá (con)vividos propiciou a essas mulheres momentos de rememoração, reflexão e encontro consigo mesmas, com as moças que eram e com as professoras que se tornaram. Dessa conclusão vêm a segunda questão sobre as entrevistas.

Em determinado momento das narrativas, os sujeitos passaram a relacionar o momento de entrada na "Escola das Madres", ou as experiências lá vividas, com as professoras que se tornaram. Magda ${ }^{6}$, uma das entrevistadas relembra que:

a educação era assim, a educação lá era muito rígida, sabe!? Severa. As madres eram exigentes. Por um lado foi bom, que a gente foi aprendendo a ter muita responsabilidade desde novinha.

Mesmo lá no colégio, eu procurava ser sempre assim, é... eu era assim, muito esforçada. Muito responsável, sabe!? Mesmo na disciplina, era assim,muito...@muito@, eu era muito disciplinada.

Sobre o caráter de exigência da escola, Odda relata que as madres-professoras:

cobrava[m] muito da gente para no futuro cobrava[cobrássemos] muito dos outros né? Acho que a intenção delas era essa né? Então a gente não podia fazer bagunça, a gente não podia conversar, tinha que ser @ ser muito certinha@.

Mais à frente, a ex-normalista completa "eu sou do sistema meio rigoroso, eu cobrava muito dos meus alunos." É possível considerar, portanto, que de alguma forma as normalistas ligam uma característica suas como professora, com a formação recebida durante os anos da escola. Não apenas o ensino mais o ideário como professora.

A tendência de utilizar os modelos de professores da vida escolar já foi bem discutida por Tardif. Segundo esse autor

Os alunos passam pelos cursos de formação de professores sem modificar suas crenças anteriores sobre o ensino. E, quando começam a trabalhar como professores, são principalmente essas crenças que eles reativam para solucionar seus problemas profissionais. (TARDIF, 2000, p.13.)

\footnotetext{
${ }^{6}$ Durante a gravação das entrevistas foi perguntado às entrevistas sobre o uso de seus nomes verdadeiros o que foi prontamente consentido. Frisa-se ainda que devido ao caráter dos dados, optou-se por utilizar a formatação de citação, no entanto usando o itálico como forma de diferenciar as narrativas das discussões teóricas. O trecho entre “@” sinaliza fala dita entre risos.
} 
Nesse sentido que se percebe a importância da Escola das Madres para a configuração dessas mulheres e ainda para a formação de professoras primárias na região. Importa ainda ressaltar que as entrevistas permitiram compreender alguns aspectos essenciais sobre a importância de se tornar professor $a$ para vida dessas mulheres.

\section{As narrativas: um olhar mais cuidadoso}

Ao tratar da feminilização do magistério na educação pública de Minas Gerais, Magda Chamon destaca alguns aspectos e questões que são bastante pertinentes no que tange à análise das narrativas das normalistas.

Primeiramente a autora ressalta que diversos trabalhos têm destacado que, na maioria das vezes, as possibilidades de profissionalização para as mulheres estão ligadas aos papéis e atributos tradicionalmente designados ao gênero feminino.

ou seja, aqueles papéis profissionais que são extensos ao trabalho doméstico - característicos do mundo privado. Às mulheres, tem sido atribuído o trabalho reprodutivo não só a nível biológico, mas também em nível social, como se esse trabalho fosse inerente à natureza feminina. (CHAMON, 2005, p.17.)

Quando a autora coloca a questão do papel reprodutivo da mulher, ela compreende reprodução para além dos aspectos biológicos. Considera, portanto, que a sociedade atribuiu à mulher, através de um processo longo e lento de convencimento e persuasão, que é papel dela reproduzir nas novas gerações os valores, comportamentos e hábitos tidos como moralmente aceitos. A frase de Magda durante a entrevista retrata bem essa compreensão, "Na nossa época, todas as moças faziam o normal... Então, desde pequena eu já estava com essa consciência né? de que ia ser professora..."

As reflexões de Chamon vão além ao considerar como as estreitas relações entre educação, capitalismo, expropriação do saber e exploração salarial impostas pela forma de organização e fragmentação do trabalho daqueles que fazem a educação auxiliaram na formação de um grupo de professoras.

$\mathrm{O}$ viés e apelo salarial aparecem nas falas das normalistas, ao atrelar a posição laboral que ocuparam como a única - ou umas das poucas - limitadas para as moças da época.

$\mathrm{Na}$ época [a profissão] era bem mais valorizada do que hoje, tanto financeiramente, quanto socialmente né? (Odda)

Aqui é cidade do interior, quase não tinha serviço para nós. Ou você era professora ou você era bancaria, ou então atendente de loja, ser professora era melhor. (Odda)

Essas mulheres, hoje, discorrem que as possibilidades inexistiam. Embora, mais a frente na narrativa a própria entrevistada relata a existência de um curso de contabilidade na cidade onde as moças poderiam ingressar. Sendo ela mesma uma dessas alunas. Reflete-se, portanto que, tal como discute Marx em 18 Brumário, a ideologia é um processo dinâmico que há um só tempo, significa a expressão e a compreensão do real, constituindo um registro próprio: o imaginário. 
No entanto, Chamon (2005) destaca que apenas as relações materiais e capitalistas não explicariam o processo de formação de toda uma classe - ou parte maior dela - em torno do feminino. Para a autora, foi-se amalgando nas mentalidades ideias de amor, ética e virtude como características do fazer pedagógico.

As perspectivas de missão sagrada, de dignidade do ofício, de valorização da abnegação e de zelo, só comparáveis às causas religiosas e patrióticas, foram incorporadas ao ethos da idealização da professora da escola elementar. (CHAMON, 2005, p. 16)

A ideia de missão, da virtude e do amor à profissão aparece nas memórias de Magda de forma bastante pungente. Ressalta-se ainda que, num momento em que o sujeito fala de si como profissional, ela também assinala que o amor à profissão, foi o que primeiro lhe foi ensinado na "Escola das Madres":

Que a gente aprendia com ela em primeiro lugar, sempre muito amor, amor a profissão. Se vocês, logo quando chegamos, se vocês querem ser professoras, em primeiro lugar vocês tem que ter amor a profissão. Se entregar, então foi isso que a minha vida inteira eu fiz, sempre com muito amor, muita dedicação. (Magda)

Nesse sentido, corrobora-se a ideia da escola como reprodutora de mentalidades que são sociais, e de perpetuadora de visões sobre a profissão já tida como feminina. Segundo Chamon, essas mulheres foram conduzidas a se conformarem com a sua subordinação e internalizaram essa resignação na formação de suas identidades pessoais. Em sua grande maioria, elas têm de si próprias uma imagem cujo componente básico é um destino social determinado pelo sexo.

Na verdade não. Não, foram circunstâncias. Porque eu, meu sonho sempre foi ser bancária [...] mas as circunstancias da época me levaram a dar aula. (Odda).

Na minha época todas as moças teriam que ser professoras né, elas não poderiam fazer assim... por exemplo, trabalhar numa repartição pública, mista principalmente. Teria que ser assim, numa escola, onde havia somente mulheres. Isso mudou e para muito melhor... (Magda)

A autora assinala ainda que a imagem que as mulheres construíram de si mesmas, atravessadas por força das ideologias de gênero acabam por interferir na sua capacidade de autoconfiança e decisão. Tais "busca torná-las inseguras, domesticadas e passíveis de manipulação, segundo as conveniências da situação.” (CHAMON, 2005, p.28, grifo da autora.)

Essa questão pode ser bem explicada quando Odda relembra pouco depois de se formar na escola normal. A jovem ex-normalista havia decidido se mudar para a capital, Belo Horizonte, para buscar estudar e prestar vestibular para Odontologia. 
Ai, eu era muito agarrada com minha mãe! Aí eu chorava, minha filha, para ir para Belo Horizonte e toda sexta-feira vinha para Oliveira. Todo domingo eu ia para Belo Horizonte, e era aquele choro, eu ia chorando e minha mãe ficava chorando. Foi isso o ano inteiro, quando foi no ano seguinte, eu com as malinhas prontas, falei: Mãe, eu vou ficar com a senhora, se eu arrumar emprego arrumei, se eu estudar estudei, mas eu não vou embora daqui mais. Ela falou: ah minha filha, a gente procura te dar o melhor, mas se você acha que o melhor é ficar, então você fica. (Odda)

Na história narrada fica a compreensão do sujeito hoje sobre o que lhe impôs a decisão do passado. Embora, em seu olhar, pesem a juventude e a indecisão de uma ex-normalista do interior em enfrentar a capital mineira, sob o olhar do pesquisador compreende-se a noção da mulher que se sente imposta pelas circunstâncias a tomar seu lugar na sociedade.

\section{As narrativas: lacunas a serem preenchidas}

Muito embora, os dados aqui apresentados sejam pequenos diante do desafio de compreender a profissão docente como espaço eminentemente feminino, fica a noção de que a construção das identidades femininas, bem como da profissão docente, pode ser compreendido a partir de um contexto histórico-cultural e das intersecções da vida cotidiana e dos aspectos econômicos e políticos vinculados às relações de trabalho, mas também de subordinação e dominação.

Os dados demonstraram ainda as lacunas no campo de discussão tanto das relações de gênero e de profissionalização docente, quanto relativo às escolas normais. Em especial aquelas que contribuíram para a formação de grande parte do professorado no interior, mostrando-se como um convite aos pesquisadores da História da Educação e da Formação de Professores.

\section{Referências}

AMARAL, Rosemary Maria do. A Educação em Oliveira pela ótica da Gazeta de Minas: uma história. In.: ALMEIDA, Márcio; RIBEIRO, João Bosco. História Contemporânea de Oliveira. Oliveira/MG: Editora Gazeta de Minas. 2011.

CHAMON, Magda. Trajetória de feminilização do magistério: ambiguidades e conflitos. Belo Horizonte: editora Autêntica/FCH-FUMEC. 2005.

CUNHA, Renata Cristina. A pesquisa narrativa: uma estratégia investigativa sobre o ser professor. V Encontro de pesquisa em Educação da UFPI. Teresina, PI. 2009. Disponível em: http://www.ufpi.br/subsiteFiles/ppged/arquivos/files/eventos/evento2009/GT.2/35_Renata\%2 0Cristina\%20da\%20Cunha.pdf Acesso em 16/03/2014

FERRAROTTI, Franco. Sobre a autonomia do método biográfico. In: NÓVOA, A.; FINGER, M. (Org.). O método (auto)biográfico e a formação. São Paulo,SP: Paulus, 2010. p.31-57.

FREITAS, Maria Teresa Menezes; FIORENTINI, Dario. As possibilidades formativas e investigativas da narrativa em educação matemática. Horizontes, v. 25, n. 1, p. 63-71, jan./jun., 2007. 
MARX, Karl. O 18 de Brumário de Luís Bonaparte. [tradução e notas Nélio Schneider ; prólogo Herbert Marcuse]. São Paulo: Boitempo, 2011.

MIGNOT, Ana Chrystina Venancio. Diários, formação e projeto pedagógico da escola: memória em construção. In: TV Escola, Salto para o futuro. Boletim 01. Março de 2007. p.41-48.

MELLO, Dilma Maria de. Histórias de subversão do currículo, conflitos e resistências: buscando espaço para a formação do professor na aula de língua inglesa no curso de Letras. 2004. 225f. Tese (Doutorado em Linguística Aplicada e Estudos de Linguagem) - Pontifícia Universidade de São Paulo, São Paulo, 2004.

PASSEGGI, Maria da Conceição; SOUZA, Elizeu Clementino; VICENTINI, Paula Perin. Entre a vida e a formação: pesquisa (auto)biográfica, docência e profissionalização. Educação em Revista, Belo Horizonte/MG, v.27, n.01, p.369-386. abr. 2011

ROSSI, Michelle Pereira da Silva; INÁCIO FILHO, Geraldo. As congregações católicas e a disseminação de escolas femininas no Triângulo Mineiro e Alto Paranaíba. Revista HISTEDBR On-line, Campinas, n.24, dez. 2006. p.79-92

SOUZA, Carla Zottolo Villanova. No mundo das normalistas: as representações da futura professora nas páginas das revistas Instituto e Normalista (1941-1953). 2007. 125f. Dissertação (Mestrado em Educação) - Faculdade de Educação, Universidade do Estado do Rio de Janeiro, Rio de Janeiro/RJ, 2007.

TARDIF, Maurice. Saberes profissionais dos professores e conhecimentos universitários. In: Revista Brasileira de Educação. No 13. Jan/Fev/Mar/Abr 2000. p. 5-24.

TANURI, Leonor Maria. História da formação de professores. Revista Brasileira de Educação. $\mathrm{N}^{\mathrm{o}} 14 \mathrm{Mai} / \mathrm{Jun} / \mathrm{Jul} /$ Ago 2000. p. 61-88. 